\title{
Impaired Balance
}

National Cancer Institute

\section{Source}

National Cancer Institute. Impaired Balance. NCI Thesaurus. Code C122435.

A deficit in equilibrium, which may manifest as unsteady ambulation or inability to

maintain an upright position. 